\title{
E-Lifestyle Conceptualization: Measurement Model Validation Using Variance Based Structural Equation Modeling (SEM-PLS)
}

\author{
Siti Hasnah Hassan ${ }^{1}$, T. Ramayah ${ }^{1}$, Osman Mohamed ${ }^{2} \&$ Amin Maghsoudi $^{1}$ \\ ${ }^{1}$ School of Management, Universiti Sains Malaysia, 11800 Penang, Malaysia \\ ${ }^{2}$ Faulty of Management, Multimedia University, 63000 Cyberjaya, Malaysia \\ Correspondence: T. Ramayah, School of Management, Universiti Sains Malaysia, Pulau Pinang, Perak, 11800, \\ Malaysia. Tel: 604-653-3889. E-mail: ramayah@usm.my
}

Received: September 27, $2014 \quad$ Accepted: October 1, $2014 \quad$ Online Published: January 28, 2015

doi:10.5539/mas.v9n2p307

URL: http://dx.doi.org/10.5539/mas.v9n2p307

\begin{abstract}
The purpose of this paper is to examine the epistemic nature of e-lifestyle conceptualization and to asses a proposed second-order formative-formative model for consumer e-lifestyle. Through a two-step approach of formative-formative model using partial least square analysis, the four constructs of consumer e-lifestyle was assessed and validated. The empirical results reveal the absence of multicollinearity while nomological, and discriminant validity were affirmed. This study has confirmed the e-lifestyle model as formative first-order and second-order hierarchical latent construct which was previously operationalized by means of reflective dimensions. This investigation merely represents a starting point in e-lifestyle conceptualization using SEM-PLS. To improve the validity and generalization of the scale proposed in the study, further cross-cultural validation through a greater population is recommended. Beyond validating e-lifestyle model as a second-order construct, this study is able to provide ample opportunity for marketers to know more about the weight and importance of each dimension of e-lifestyle. This research contributes to current consumer behavior literature on what factors affect consumer e-lifestyle that pave a way for marketers to have a better understanding toward their consumer e-lifestyle and hence execute related marketing strategies.
\end{abstract}

Keywords: consumer e-lifestyle, reflective measurement model, formative measurement model, partial least square analysis, second-order construct, Malaysia

\section{Introduction}

Recently, remarkable growth is observable in the mobile communication market around the world. Specifically, more people use Internet services on the mobile phones compared to before as it is more convenient and facilitates the communication. Indeed, the trend has considerably influenced and altered the way people live in the current environment. In addition to that, understanding consumer lifestyle has extensively been conceived beneficial in tailoring appropriate product and/or services to particular target segments, that has provided ample opportunity exist to conceptualize an e-lifestyle instrument (Yu, 2011). By doing so, marketing management could be able to build a better strategic planning based on understanding their potential consumer's lifestyle toward using particular product and/or service. Remarkably, many advertisers prefer to profile their brand relying on consumer lifestyle, as different brands within a product and/or service segment are commonly hard to distinguish in terms of product and/or service attributes (Biel, 1992). In the similar sense, Hornik (1989) notes the premise of psychographics is that the more we know about the people's lifestyle, the more we can understand, communicate and respond to them effectively. Consequently, it is obvious that marketing communication is more effective when consumer lifestyles are fully understood. In another word, lifestyle research is of capital interest for managers to visualize their audiences more appropriately (Vyncke, 2002).

Lifestyle studies are prevalently based on extensive surveys using quantitative methods (Vyncke, 2002). Lifestyle was studied using large set of activities, interests, and opinions (AIO) rating statements developed by Wells and Tigert (1971). Plummer (1977) conceptualized the notion of lifestyle term in generic perspective without statistical results. Kucukemiroglu (1999) used AIO statements to measure Turkish consumer's belief toward their activities, interests and opinions. Their analysis extracted eight factors explain 68.55 percent of variance; however, they didn't consider consumer values in lifestyle measurement model. This can be explained by the notion that individual's value preferences are part of their basic worldviews (Struch et al., 2002), and 
hence important determinants of lifestyle (Vyncke, 2002). Vyncke (2002) used cluster analysis to conceptualize lifestyle from different lenses including ad hoc AIO surveys and stable terminologies of values, esthetics styles and life visions. However, their study is lacked providing statistical support for the measurement instruments.

More recently, Lee et al. (2009) conceptualized consumer lifestyle in terms of four distinct factors incorporating e-shopping preference, Internet involvement, fashion consciousness, and leisure orientation. Reliability value for each constructs was moderate (ranged about 0.75 ) and all factors considered reflective while they are different in nature. Yu (2011) operationalized e-lifestyle incorporating AIO and VALS rating statements. Yu (2011) deployed reflective measurement model for each construct (e.g., e-activities, e-interests and etc.), while items for each construct carried different contents. In terms of e-activities, 13 items were asked from the respondents reflectively, however, each item is about different type of activity. For example, the ranges of activities start from using Internet to perform job, to participate social event and arrange trips which are completely different in meaning and hence each carries different weight. Therefore, it would be odd to group them as reflective indicators, but rather formative as each carries different weight. Consequently, marketers will be confused about the major activities which are preferred by the consumers.

Previous literature on consumer lifestyle has being plagued with inconsistency with regard its correlation with consumer behavior failed to satisfy marketers' needs (Vyncke, 2002). These empirical pitfalls reveal that more measurement-related empirical studies need to be conducted. In fact, the potential doubt has risen to either consider AIO and VALS rating measurement indicators as reflective or formative indicators for construct of e-lifestyle. In fact, measurement models are commonly misspecified in empirical efforts (Podsakoff et al., 2006). According to Podsakoff et al. (2006), measurement model misspecification is conceived as latent variable having formative measure are incorrectly specified as having reflective measurement or vice versa. Consequently, measurement model misspecification can affect the estimates of the measurement and structural model parameters (Jarvis et al., 2003). In respect to these concerns, the study intends to assess the measurement model specification of e-lifestyle using AIO and VALS rating statements with four dimensions, namely, e-activities, e-interests, e-opinions, and e-values. Although, e-lifestyle was validated previously by $\mathrm{Yu}$ (2011), this study used different validity assessment tool in the context of Malaysian consumers. In particular, this study implemented a second-order construct for e-lifestyle in order to reduce complexity in the model (Hair et al., 2013). Moreover, previous studies considered e-lifestyle as a reflective measurement model, while there are some dissimilarity among the group of dimensions that need to be formatively defined. Furthermore, previous studies has discussed the lifestyle instrument which established initially in the late 1970s and early 1980s (Lin, 2003). Therefore, the findings might not be appropriately capturing the consumer's lifestyle in today's real world due to boom of technology and various Internet services applications (Chen and He, 2006). This study, hence, contributes to the emerging consumer behavior literature pertinent to consumer lifestyle by focusing on its measurement model assessment.

Based on above argument, the primary goal of the research is to validate first-order and second-order construct of e-lifestyle that could provide marketers beneficial insights of what triggers consumer's e-lifestyle when they use particular services. Accordingly, subsequent section includes review of literature dominantly related to the lifestyle and e-lifestyle. Given the extant literature review, construct of e-lifestyle is developed and tested within the defined sample group. Measurement assessment and two-step approach (i.e., repeated method) were used conducting Partial Least Square (PLS) analysis. Finally the results are discussed and conclusion has been addressed.

\section{Conceptual Differences between Reflective and Formative Measurement Model}

Generally, the measurement model stipulates the association between the measurement items and the underlying latent variables (Chin, 1998). In particular, the association between the measurement items and the underlying latent variables can be either formative or reflective, or both formative and reflective in nature (Fornell and Larcker, 1981). The decision, whether to choose reflective or formative, have to be based on theoretical considerations (Gotz et al., 2010).

Indeed, the formative and reflective measurement models differ at theoretical and nomological point of views (Petter et al., 2007b). From theoretical standpoint, reflective measurement models are conceived as manifestation of the latent variable, while formative model provides a means of measured variables defining the characteristics of correspondent latent variable (Hair et al., 2013). In the similar sense, when a latent variable (e.g., e-lifestyle in this research paper) is measured by some formative indicators, it is presumed that the observed indicators cause the latent variable. Conversely, when a latent variable is measured by some reflective indicators, it is assumed that the latent variable causes the indicators (Bollen, 1989). Additionally, from nomological standpoint, previous 
research compare between formative and reflective measurement models mainly based on four prominent criteria including direction of causality, interchangeability of the measures, correlation among the measures and nomological net (Jarvis et al., 2003).

\section{Previous Research on Consumer E-Lifestyle}

Traditional segmentation strategies are based on individual socio-demographic, attitudinal, or psychographic characteristics (Penz, 2006). The term psychographic puts together 'psychology and 'demographics' to add richness of both social and behavioural sciences to demographics in order to improve understanding of consumer behaviour (Demby, 1974). The first spectrum of psychographic studies was originally rooted in personality profiles with the most frequently used scale for measuring general aspects of personality traits. However, these researches being plagued with inconsistent correlations with consumer behaviour (Vyncke, 2002). In the second spectrum of psychographic research, concept of personality has been replaced by concept of 'lifestyle' which was introduced by Lazer (1963). To date, the term lifestyle has become prevalent amongst scholar in the field of consumer behaviour, and hence, the term is used in this research.

Lifestyle is commonly referred to patterns in which people live and spend their time and money (Kaynak and Kara, 2001). Lifestyle can also be defined as patterns of action which differentiate people in order to help to understand what people do and why they do it (Chaney, 1996). Accordingly, the term lifestyle has become central, while the personality concept has become marginal to psychographic studies and the latter is currently replaced by lifestyle concept (Vyncke, 2002). The term lifestyle is rather widespread than that of socioeconomics and demographic characteristics (Blackwell et al., 2001). More importantly, individual lifestyles seem to be more effective predictor of consumer behaviour including disposition and use of products and services (Murry et al., 1997). Thereby, decision makers will be able to connect to their consumers strongly by recognizing the lifestyle characteristics of potential consumers (Lee et al., 2009).

Hyper merging of the Internet and mobile usage, particularly among the youth, has dramatically impacted and shaped the way people live since last decade (Yu, 2011). Therefore, understanding the consumer lifestyles has been reflected useful in bringing suitable products and/or services to particular target segments of information and communication technology and hence, concept of e-lifestyle has been introduced that could help marketers to decide precisely within this target segment (Chen and He, 2006). Furthermore, Yu (2011) develops and validate an e-lifestyle construct that could offer marketers some understandings of what triggers people's e-lifestyles. E-lifestyle, in this research, conceives as patterns in which people live and spend their time and money through Internet and electronic, which this definition is consistent with that of Kaynak and Kara (2001). Lifestyle theories agreed that consumer behaviours can be anticipated toward sociological and psychological variables. Consistently, consumer e-lifestyle is also predictable and assessable by psychological and sociological constructs (Yu, 2011).

Myriad of researches have assessed the lifestyle construct, but among various lifestyle scales, two conceptualizations are popular and broadly used. The first one is lifestyle's construct conceptualizing by three dimensions of activities, interests, and opinions (AIO), originally developed by Wells and Tigert (1971). The second construct includes value, attitude, and lifestyles (VALS) rating scale, which operationalized by seminal work of Mitchell (1983). Wells and Tigert (1971) defined activities as "actual observable behaviours, interests as the continuous paying of attention to certain objects, and opinions as responses to specific events". Since then, lifestyle has been conceptualized based on AIO approach extensively to help marketers tailoring particular service and/or product to various target segments (Bates et al., 2001, Green et al., 2006, Hur et al., 2010).

Mitchell (1983) developed VALS instrument by observing the associations between individual actions, values, lives, and beliefs. He explained that combination of perceived value and personal life can identify the consumer behaviour, while perceived value is a synthesis of individual beliefs, hopes, demands, and attitudes. Therefore, many scholars argue that value is one of the necessary constructs, beside activities, interests, and opinions, to assess consumer lifestyle (Lin, 2003). Interestingly, in parallel with that, $\mathrm{Yu}$ (2011) operationalized e-lifestyle employing four reflective dimensions of e-activities, e-opinions, e-interests, and e-values. Furthermore, lifestyle is a set of behaviours mirroring individual psychological concerns (i.e., internal beliefs) as well as sociological consequences (i.e., external stimuli) (Yu, 2011). However, this research raises the confusion on considering the dimension of e-lifestyle as either reflective or formative.

In essence, the dimensions of e-activities, e-interests, e-opinions, and e-values shape the psychographic characteristics of the individual consumers by contributing unique measures of AIO and VALS rating scale. Combing the indicators capture the entire concept of e-lifestyle which defined as the collective pattern of action which differentiate people in order to help to understand what people do and why they do. By inspection, the 
four indicators of e-lifestyle reveal the causal priority flows from the indicators to the construct of e-lifestyle, but not the other way round. It is obvious, the way individual consumers do their activities or believe about a particular objects, frame their lifestyle, while the other way round may not be plausible.

With regard to interchangeability of the measures, the definitions of the e-activities, e-interests, e-opinions, and e-values do explain different theme based on each perspective definition and hence do not share common thoughts about the phenomena. Therefore, it is odd to interchange one dimension by another as it may not shed light under umbrella of e-lifestyle. Thereby, dropping one dimension might change the conceptual domain of lifestyle. These features contradict concerting the reflective measurement models. More specifically, these four dimensions might have positive or negative correlation to each other. Therefore, they are not expected to be highly correlated which is a necessary condition for the reflective measurement models. Consequently, changes in one dimension and/or indicator may not be related to changes in other dimension or indicator. Overall, the dimensions of e-activities, e-interests, e-opinions, and e-values are obviously not interchangeably; hence have potential different antecedents and outcomes. Indeed, they would not essentially covary and correlate with each other. As a result, the latent constructs of e-lifestyle can be viewed as formative measurement models. Indeed, lifestyle's dimensions can be specified as a hierarchical latent variable constituted by its four dimensions. Furthermore, each dimension involves certain formative indicators with each indicator includes different, for example, activity or interest. In relation to this, the e-lifestyle conceptualization can be specified as a second-order formative-formative model.

\section{Method}

\subsection{Sample and Data Collection Procedure}

A self-administered questionnaire distributed among university students from several regions in Malaysia. The unit of analysis in this study is mobile subscribers (consumers) of the prominent service operators (i.e., Celcom, Digi, Maxis, and Umobile) within some areas in Malaysia that become the sub-region of continuous development, progress, wealth, peace and quality of life according to the five-year IMT-GT Roadmap (ADB, 2008). The covered area in Malaysia includes states of Kedah, Perlis, Perak, Penang, Selangor, Kelantan, Melaka, and Negeri Sembilan. Based on rule of thumb, the minimum number of respondents is five-to-one ratio of the number of latent variables to be tested. Since we were not able to obtain a list of total population in the suggested area, thereby a non-probability purposive sampling approach is employed whereby only mobile subscribers of the four particular mobile providers in Malaysia were chosen and the rest were excluded from the data set. Purposive sampling method was used as the list of populations was not available. About 600 self-administered questionnaires were used for gathering data from the respondents in Malaysia. A total 197 valid questionnaires were received by end of data collection's period $(32.8 \%$ response rate).

\subsection{Measures}

The e-lifestyle instrument which was originally developed by Wells and Tigert (1971), and Mitchell (1983) under theme of lifestyle and adapted by seminal work of Yu (2011), was adapted in this study. The questionnaire comprised of 28 items to measure the dimension of e-activities ( 8 items), e-interests ( 7 items), e-opinions (6 items), and e-values (7 items). The questionnaire with a five-point Likert scale, ranging from 1 (strongly disagree), to 5 (strongly agree) was used to collect the data.

The instrument was hence adapted based on Malaysian-response context. The questionnaire consists of two major sections. First section included four sub-constructs underlying consumer e-lifestyle. Construct of e-lifestyle is considered as second-order construct. Four first-order constructs are defined for the e-lifestyle construct which were adapted from previous research (Wells and Tigert, 1971, Yu, 2011, Mitchell, 1983). Previous studies employed all indicators as reflective indicators, however its flawed because some indicators carried different weight. Therefore, they need to be served as formative items. Last section gathers demographic information of the respondents such as gender, age, race, and education level. Table 1 provides the items for each sub-construct underlying construct of e-lifestyle.

Table 1. Dimension of e-lifestyle and its item description

\begin{tabular}{lll}
\hline Dimension & Item & Description \\
\hline E-activities & & I frequently use Internet on my mobile to .... \\
& EA1 & play games or listen to online music \\
& EA2 & shop for products/services. \\
& EA3 & share my opinions within network communities (e.g., Facebook, Twitter, etc.) \\
\hline
\end{tabular}




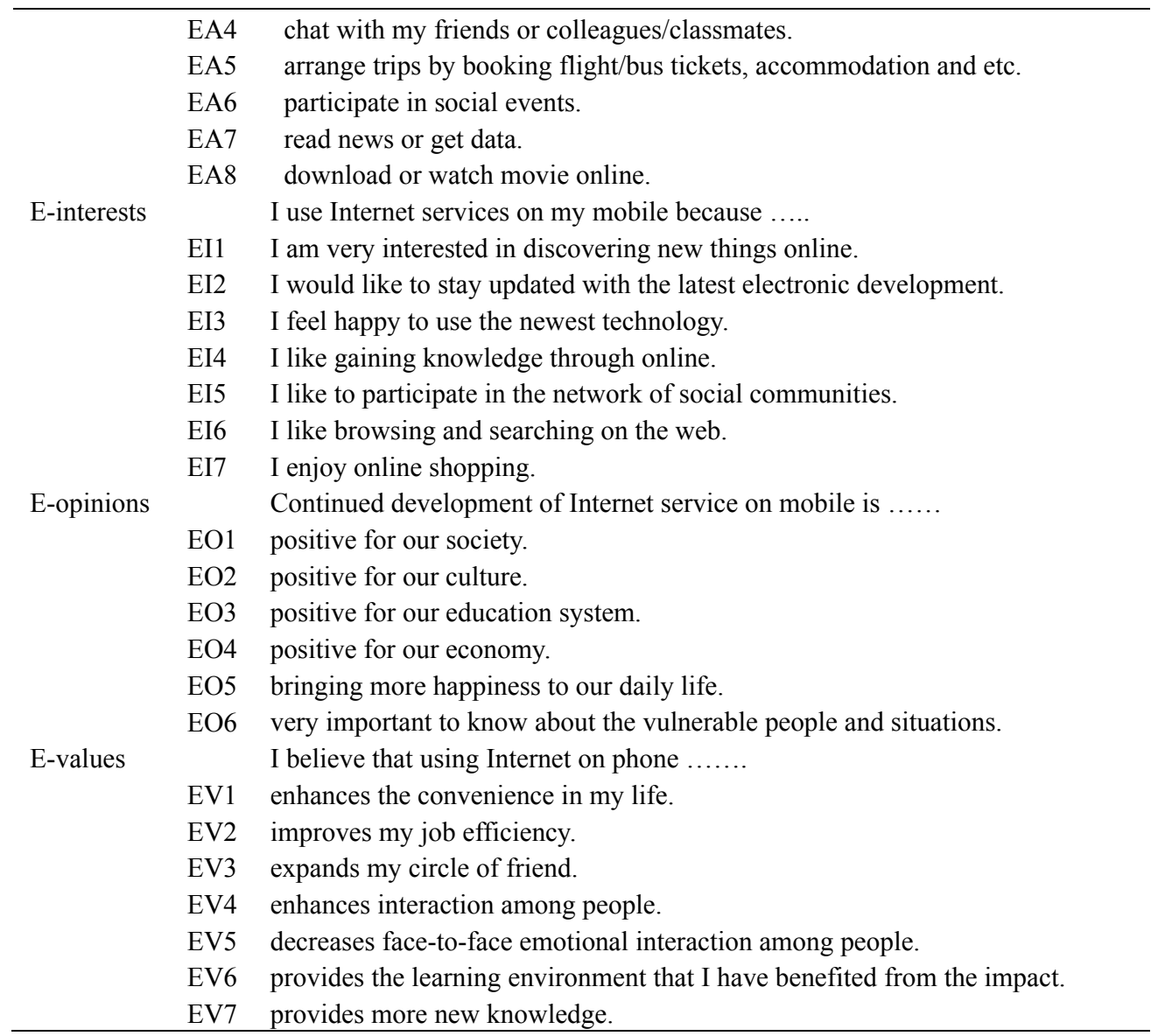

\subsection{Data Analysis Technique}

Higher-order construct is a general concept that is either formed or reflected by its dimensions as a lower-order constructs (Becker et al., 2012). Generally, the nature of relationship between the second-order and first-order construct is categorized in four types of second-order latent variables (Jarvis et al., 2003, Hair et al., 2013). First, the reflective-reflective type 1 model with the lower-order constructs are reflectively measured constructs. Second, the reflective-formative type II model with higher-order construct is a common concept of several formative lower-order constructs. Third, the formative-reflective type III model with the higher-order construct is common concept of several particular formative lower-order constructs. Finally, the formative-formative type IV model with the lower-order constructs are formatively measured constructs that form a general concept of higher-order construct. For the purpose of this research, formative-formative type IV model as illustrated in Figure 1, has been conducted (refer to the argument in section 3 ) in order to validate the measurement instrument for the latent variable construct of e-lifestyle. SmartPLS 2.0 software (Ringle et al., 2005) was used to validate the e-lifestyle instruments by conducting partial least squares (PLS) analysis. PLS was preferred as the methodological choice due to several reasons. 


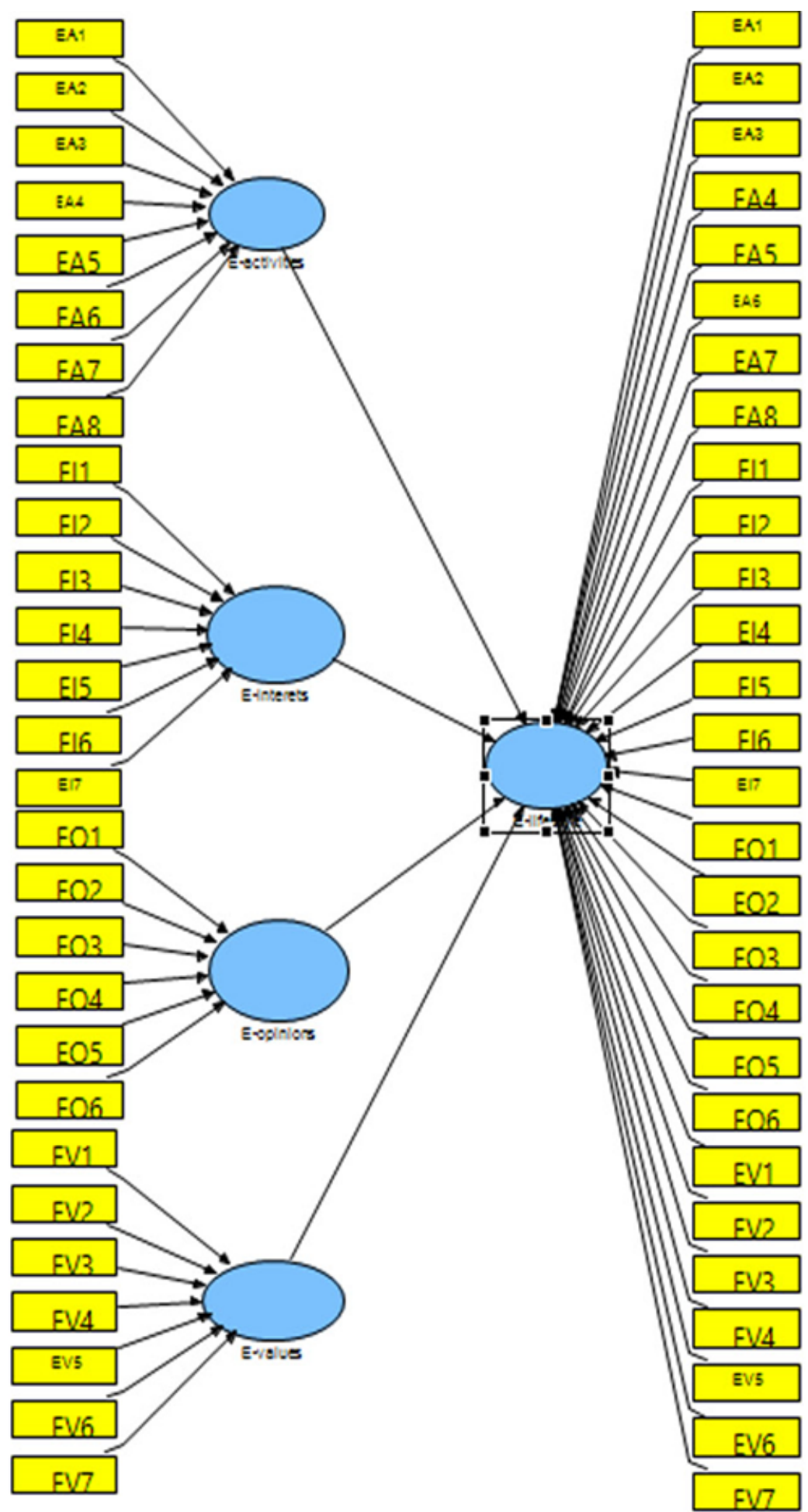

Figure 1. Illustration of repeated indicator approach

First, as a variance-based approach, it places minimal requirements on residual distributions and sample size to achieve a satisfactory numerical power (Hair et al., 2012). Second, it is advance the choice to analysis constructs' association comparing to other technique (Acedo and Jones, 2007). Third, it allows us to simultaneously evaluate both measurement and structural model (Chin, 1998), while it eliminates concerns about the multicollinearity issues (Inkpen and Birkenshaw, 1994). Fourth, it allows to analysis data during the early stage of theory development (Tsang, 2002). 
In line with the purpose of this research, the dimensions of e-activities, e-interests, e-opinions, and e-values are manifested by its respective item measures (see Table 1). Additionally, these four dimensions do not share a common theme capture the conceptual domain of consumer lifestyle, and their respective item measures capture also different theme with respect to type of activity, interest, opinion and values. Therefore, the relationships between e-lifestyle and its four dimensions concur with the nature of relationship higher- and lower-order construct as illustrated in Figure 1, represents a second-order formative-formative type IV model. As such, e-lifestyle is then characterized as hierarchical latent construct in the form of second-order formative-formative type IV model in this study. The repeated indicator approach was implemented to assess the second-order formative-formative type IV model due to its advantage to estimate all variables and indicators simultaneously in order to avoid interpretational confusion (Becker et al., 2012). In particular, four dimensions of e-activities, e-interests, e-opinions, and e-values are termed as first-order constructs. According to Figure 1, repeated indicator approach is depicted when the second-order construct, namely, e-lifestyle was directly assessed by the corresponding first-order constructs and in turn these four first-order constructs were directly estimated by its underlying formative measures.

In relation to this, the relationship between of e-activities, e-interests, e-opinions, and e-values and its receptive formative measures was determined at first-order construct level. Thereafter, the relationship between the consumer e-lifestyle and the four first-order constructs was examined at second-order level. This study used PLS analysis to estimate the parameters in both first-order formative model and second-order formative model with a path weight scheme (Johnson et al., 2012). Additionally, the study applied bootstrapping with resampling 5000 replications to achieve the standard error of the estimates (Efron and Tibshirani, 1994). Following the Hair et al (2013) guideline, the analysis was conducted on two levels of the first-order constructs and second-order constructs level.

\section{Results}

We followed the guidelines of Hair et al. (2013) to report the PLS-SEM approach. Since PLS-SEM is nonparametric approach, therefore it does not require the data to be normally distributed. However, it is important to verify data are not far from normal distribution. Subsequently, skewness and kurtosis were used prior to data analysis to evaluate the extent to which a variables' distribution is symmetrical (Hair et al., 2013). The skewness and kurtosis values of most items ranged between -1 and +1 , which are well below the levels suggested for transformation of variables (Ghisseli et al., 1981). Thereby, non-normality of data is not an issue for the research. The following discusses about the results of the study.

\subsection{Common Method Variance}

Furthermore, common method bias was assessed by conducting Harman's single factor (Podsakoff et al., 2003). Accordingly, single factor accounted for the majority of variance explained (19.149\% only). This suggests that common method bias is not a major issue in this study.

\subsection{Demographic Profiles of Respondents}

Table 2 depicts the demographic profile of 197 respondents in Malaysia. The demographic profile includes the respondent's gender, age, race, highest education level, monthly salary, monthly mobile subscription and their most recent subscription.

Accordingly to Table 2, the respondents who are female are more than double that of the number of male respondents with rate of $68.7 \%$ female versus $31.3 \%$ male. Age of respondents in this category varies differently. In fact, about $70 \%$ of respondents aged between 18 and 22 years old, while only $30 \%$ of respondents aged between 22 and 37 years old. Therefore, the results show that the majority of respondents are in the range of generation Y (i.e., birth date years between 1980s and 2000s). More than half of respondents are Chinese based $(58.2 \%)$, while 28.6 are Malay and only $1.5 \%$ of respondents are Indians. Majority of respondents are educated having bachelor degree (65.8\%), master (15.8\%) and $\mathrm{PhD}(6.6 \%) .77 \%$ of respondents have monthly salary of less than RM1000, which show majority were students at the university level, while the rest of respondents with salary above that amount.

Table 2. Demographic profile of respondents $(\mathrm{n}=197)$

\begin{tabular}{llcc}
\hline Variable & Categories & Frequency & Percentage \\
\hline Gender & Male & 61 & 31.3 \\
& Female & 134 & 68.7 \\
\hline
\end{tabular}




\begin{tabular}{|c|c|c|c|}
\hline \multirow[t]{4}{*}{ Age } & $18-22$ & 128 & 69.9 \\
\hline & $23-27$ & 25 & 13.6 \\
\hline & $28-32$ & 19 & 10.3 \\
\hline & $33-37$ & 11 & 5.8 \\
\hline \multirow[t]{4}{*}{ Race } & Malay & 56 & 28.6 \\
\hline & Chinese & 114 & 58.2 \\
\hline & Indian & 3 & 1.5 \\
\hline & Others & 23 & 11.7 \\
\hline \multirow{5}{*}{ Highest educational level } & High school (SPM) & 1 & 0.5 \\
\hline & Diploma/Matriculation/STP] & 22 & 11.2 \\
\hline & Degree & 129 & 65.8 \\
\hline & Master & 31 & 15.8 \\
\hline & $\mathrm{PhD}$ & 13 & 6.6 \\
\hline \multirow[t]{6}{*}{ Monthly salary } & Less than RM1000 & 131 & 77.5 \\
\hline & RM1000-2000 & 15 & 8.9 \\
\hline & RM2001-3000 & 9 & 5.3 \\
\hline & RM3001-4000 & 6 & 3.6 \\
\hline & Rm4001-5000 & 5 & 3.0 \\
\hline & More than RM5000 & 3 & 1.8 \\
\hline \multirow[t]{5}{*}{ Monthly subscription } & Less than RM50 & 78 & 40.8 \\
\hline & RM50-100 & 75 & 39.3 \\
\hline & RM101-150 & 29 & 15.2 \\
\hline & RM151-200 & 6 & 3.1 \\
\hline & More than RM200 & 3 & 1.6 \\
\hline \multirow[t]{5}{*}{ Current subscription to mobile operator } & Celcom & 51 & 21.1 \\
\hline & Digi & 63 & 27.4 \\
\hline & Maxis & 57 & 24.2 \\
\hline & Umobile & 16 & 2.6 \\
\hline & Others & 14 & 1.6 \\
\hline
\end{tabular}

$40.8 \%$ of mobile users as respondents spend less than RM50 monthly on mobile subscription. Similarly, about the equal numbers of respondents spend monthly between RM50 and RM100 on subscription, while only $1.6 \%$ spends over RM200 on mobile subscription. In general, mobile users in Malaysia closely use different mobile network operators. It shows high competition on telecommunication sector. For example, Digi is number one in terms of subscription among the respondents by $27.4 \%$. Maxis come to the second after Digi with $24.2 \%$, and Celcom $(21.1 \%)$ respectively. Umobile is newly introduced brand to the market and has yet to be recognized among the mobile users.

\subsection{Assessment of First-Order Constructs Model}

In order to assess the validity for formative constructs at first-order construct level, several steps need to be done sequentially. First, scholars need to assess multicollinearity issue for the formative indicators (Peng and Lai, 2012). High correlations between two formative indicators can have an effect on the results as it boosts the standard error and reduce the ability to demonstrate that the estimated weights are different from zero (Hair et al., 2013). Variance inflation factor is a used means to assess the multicollinearity issue (Petter et al., 2007a). In context of PLS-SEM, a VIF value of 5 and higher indicates a potential collinearity problem (Hair et al., 2011). However, the common acceptable threshold for VIF is below 3.3 (Diamantopoulos and Siguaw, 2006). Second, scholars should assess each formative indicator's contribution to the formative construct score which is created by aggregating the formative indicators of a construct using the item's weight (Götz et al., 2010). Item's weight should be significant, the sign of item weight should be consistent with the underlying theory and the magnitude of the item weight should be greater than 0.10 (Andreev et al., 2009).

Four formative constructs (e-activities, e-interests, e-opinions, and e-values) in the research were assessed for validity using VIF and outer weighting significance results. Table 3 depicts that VIF value is lower than 3.3 for all four constructs. Hence, collinearity issues are not at critical level for the first-order constructs in this study. Therefore, first assessment's step of for the formative constructs are met, and hence item weight in formative measurement models should be analysed for their significance and relevance as the second step for formative measurement assessment (Hair et al., 2013). Bootstrapping procedure generating 5000 subsamples was used to 
test whether the outer weights in formative measurement models are significantly different from zero.

Table 3. Collinearity statistics

\begin{tabular}{cccccccc}
\hline \multicolumn{2}{c}{ E-activities } & \multicolumn{2}{c}{ E-interests } & \multicolumn{2}{c}{ E-opinions } & \multicolumn{2}{c}{ E-values } \\
\hline Indicators & VIF & Indicators & VIF & Indicators & VIF & Indicators & VIF \\
EA1 & 1.143 & EI1 & 1.480 & EO1 & 1.521 & EV1 & 1.395 \\
EA2 & 1.403 & EI2 & 1.855 & EO2 & 1.415 & EV2 & 1.582 \\
EA3 & 1.672 & EI3 & 2.088 & EO3 & 1.682 & EV3 & 1.821 \\
EA4 & 1.220 & EI4 & 1.748 & EO4 & 1.405 & EV4 & 1.738 \\
EA5 & 1.350 & EI5 & 1.447 & EO5 & 1.454 & EV5 & 1.053 \\
EA6 & 1.605 & EI6 & 1.523 & EO6 & 1.383 & EV6 & 1.776 \\
EA7 & 1.270 & EI7 & 1.128 & & & EV7 & 1.964 \\
EA8 & 1.138 & & & & & & \\
EA9 & 1.134 & & & & & & \\
\hline
\end{tabular}

Furthermore, Table 4 illustrates the assessment of formative constructs using the items weight's significance. E-activities have total nine formative items. The weights for three items are not significant (i.e., EA3, and EA6). Additionally, their outer loadings are less than value of 0.50 . Therefore, they were removed from data sample set. Seven indicators of e-interest are significant at 99, 95 and 90\% confidence level (refer to last column of Table 4). All seven formative indicators of e-interest have item's weight value above 0.10 and statistically significant. For construct of e-opinion, out of six formative indicators, four of them have item weight value above 0.10 , while EO2 and EO5 are not significant. However, since their item loading are above value of 0.50 (i.e., 0.624, and 0.567 respectively), they have to remain in the model of the study. Five indicators of e-values have item weight above value of 0.10 and significant at 99,90 , and 95\% confidence level. EV4 is not significant; however, it remained in the model as its representative item loading is above 0.50 with value of 0.645 . Moreover, EV5 have to be removed from the model, which were not either significant nor has item loading above value of 0.50 .

Table 4. Validity results for formative first-order constructs

\begin{tabular}{|c|c|c|c|c|}
\hline Formative constructs & $\begin{array}{l}\text { Formative } \\
\text { indicators }\end{array}$ & Measure & $\begin{array}{c}\text { Item weight } \\
\text { (Item loading) }\end{array}$ & T.stat \\
\hline \multirow[t]{8}{*}{ E-Activities } & EA1 & Formative & $0.163(0.254)$ & $1.704 * *$ \\
\hline & EA2 & & $0.319(0.341)$ & $2.976 * * *$ \\
\hline & EA3 & & $0.029(0.283)$ & $0.504^{\mathrm{NS}}$ \\
\hline & EA4 & & $0.322(0.558)$ & $2.840 * * *$ \\
\hline & EA5 & & $0.113(0.395)$ & $1.235^{\mathrm{NS}}$ \\
\hline & EA6 & & $0.021(0.422)$ & $0.383^{\mathrm{NS}}$ \\
\hline & EA7 & & $0.223(0.537)$ & $2.043 * *$ \\
\hline & EA8 & & $0.660(0.732)$ & $6.501 * * *$ \\
\hline \multirow[t]{7}{*}{ E-interests } & EI1 & Formative & $0.315(0.712)$ & $2.783 * * *$ \\
\hline & EI2 & & $-0.142(0.433)$ & $1.393 *$ \\
\hline & EI3 & & $0.151(0.618)$ & $1.451 *$ \\
\hline & EI4 & & $0.355(0.809)$ & $3.211 * * *$ \\
\hline & EI5 & & $0.385(0.764)$ & $3.472 * * *$ \\
\hline & EI6 & & $0.152(0.663)$ & $1.561^{*}$ \\
\hline & EI7 & & $0.159(0.386)$ & $1.747 * *$ \\
\hline \multirow[t]{6}{*}{ E-Opinions } & EO1 & Formative & $0.255(0.739)$ & $3.177 * * *$ \\
\hline & $\mathrm{EO} 2$ & & $0.086(0.624)$ & $1.176^{\mathrm{NS}}$ \\
\hline & EO3 & & $0.625(0.926)$ & $7.599 * * *$ \\
\hline & EO4 & & $0.047(0.576)$ & $1.432 *$ \\
\hline & EO5 & & $0.088(0.567)$ & $0.809^{\mathrm{NS}}$ \\
\hline & EO6 & & $0.186(0.553)$ & $2.276^{* *}$ \\
\hline \multirow[t]{4}{*}{ E-Values } & EV1 & Formative & $0.161(0.646)$ & $1.577^{*}$ \\
\hline & EV2 & & $0.147(0.709)$ & $1.632 *$ \\
\hline & EV3 & & $0.354(0.796)$ & $3.029 * * *$ \\
\hline & EV4 & & $0.032(0.645)$ & $0.412^{\mathrm{NS}}$ \\
\hline
\end{tabular}




\begin{tabular}{cccc}
\hline EV5 & $0.025(0.198)$ & $0.467^{\mathrm{NS}}$ \\
EV6 & $0.258(0.784)$ & $2.258^{* *}$ \\
EV7 & $0.333(0.839)$ & $2.759^{* * *}$ \\
\hline
\end{tabular}

Note: NS $=$ not significant. ${ }^{*} \mathrm{p}<0.10,{ }^{* *} \mathrm{p}<0.05,{ }^{* * *} \mathrm{p}<0.01$.

According to Table 4, the validity for formative measurement models first-order-constructs are assessed. The next section deals with the assessment of the second-order construct model including the four indicators of e-activities, e-interests, e-opinions, and e-values as first-order constructs for the latent variable construct of e-lifestyle as second-order construct.

\subsection{Assessment of Second-Order Construct Model}

In order to assess the formative second-order construct, the collinearity issue needs to be addressed among the four constructs. The procedure and evaluation process for collinearity issues follow the same guideline as for the first-order construct model (refer to previous section). Likewise, the assessment for the formative indicators for the second-order construct model also follows the guideline from the seminal work of Hair et al. (2013).

According to Table 5, VIF for all four indicators of construct of e-lifestyle are less than value of 3.3, therefore, there is no issue of multicollinearity problem across the indicators. Furthermore, Table 5 depicts that four indicators are highly significant at $99 \%$ confidence level. Additionally, their items weights are above value of 0.1 , hence they are accepted to be significant formative indicators for their latent variable construct (i.e., e-lifestyle).

Table 5. Validity results for formative second-order construct

\begin{tabular}{llcccc}
\hline Second-order construct & First-order constructs & Measure & Item weights & T.stat & VIF \\
\hline E-lifestyle & E-activities & Formative & 0.214 & $9.849^{* * *}$ & 1.720 \\
& E-interests & & 0.342 & $15.336^{* * *}$ & 2.019 \\
& E-opinions & & 0.335 & $13.762^{* * *}$ & 2.413 \\
& E-values & & 0.301 & $10.918^{* * *}$ & 2.070 \\
\hline
\end{tabular}

Note: $\mathrm{NS}=$ not significant. ${ }^{*} \mathrm{p}<0.10,{ }^{*} \mathrm{p}<0.05, * * * \mathrm{p}<0.01$

More specifically, the construct of e-interests carries the highest weight among the indicators with value of 0.342 , follows with e-opinions with value of 0.335 . The lowest value belongs to e-activities with 0.214 . The result confirmed considering the four dimensions of e-lifestyle as formative constructs, thereby affirming nomological validity. Moreover, the model also showed sufficient predictive relevance with $\mathrm{Q}^{2}$ of above zero value $(0.297)$. The following section involves the discussion about the achieved results and conclusion for the study.

\section{Discussion and Conclusion}

The inconsistent psychometric findings of the assessment of measurement model underlying consumer e-lifestyle provoked this research to further examine the epistemic nature of e-lifestyle in formative measures. Surprisingly, the four major dimensions of e-lifestyle to be found concurred with the key features of formative measurement models. Furthermore, this study has estimated a second-order formative-formative model of consumer e-lifestyle using the repeated indicator approach suggested by previous scholars (Becker et al., 2012, Hair et al., 2013). Indeed, the outcome of this research has provided a more rigorous psychometric result compared to the previous research which commonly measure e-lifestyle reflectively (e.g., Yu, 2011). The psychometric results can be explored through the practical evidence of measurement parameter estimates such as item weight value, the absence of multicollinearity, nomological validity in the format of second-order formative-formative model.

In particular, new insights were obtained from the result for the first-order constructs, which can add to the body of knowledge. For example, with regard to e-activities, consumers seem not do their banking transaction and/or arrange trips via online, while other activities shows high validity. Likewise, indicating the item weight for each indicator can depict significantly the importance of each from the consumer point of view. The result reveals the target group are interested to certain issues while they may not be interested to do other things throughout Internet. For example, consumers are interested to discover new things or participate in the social communities rather to enjoy online shopping. The result can help marketers to understand to what extent certain interests are important for the consumers, while other interests and hobbies may not be of interest to them.

Furthermore, the results reveals that the consumers think that using Internet is positive for their education system, while other opinions such as society, culture and etc. have become to less attention among the target group. This 
can lead to understanding that when business promote Internet services, they may introduce though of education in order to attract their potential consumer to purchase their services. Additionally, e-value included certain beliefs that bring different weights based on the results. Indeed, the sample group give priority to used Internet in order to expand their circle of friend or perceive using Internet to gain more new knowledge. This perception can help marketers to have a better understanding with regard to their potential consumer's belief about using Internet.

Overall, the results provide ample opportunity to prioritize different dimensions of e-lifestyle and compare them together. Previous literature combine and use the dimensions reflectively, hence the prioritization was difficult to recognize. Therefore, the study contributes to the lifestyle literature by revealing the importance of each dimension of e-lifestyle in the context of Malaysian consumers. Probably, marketers can increase their focus on dimensions with the higher weight (e.g., e-interest). Moreover, this study has advanced a second-order formative-formative model of lifestyle using PLS which would provide new insights for variance based SEM.

Notwithstanding, several limitations exist and hence worth to be addressed in this study. First, this study has been conducted in Malaysian context. Probably it would be noble to extend the population of the study to a wider group across Southeast Asian countries as emerging economies located. Cross-cultural analysis can be done amongst four dimensions of lifestyle. Second, the study is limited to students as the major respondents and major Internet users among the generations. The formative measurement model needs to be cross-validated in different setting. Indeed, potential opportunity exists for further studies to include different type of individual consumers in terms of their generation.

\section{Acknowledgments}

The authors would like to thank Universiti Sains Malaysia for funding this research under the Research University grant no. 1001/PMGT/816203.

\section{References}

Acedo, F. J., \& Jones, M. V. (2007). Speed of internationalization and entrepreneurial cognition: Insights and a comparison between international new ventures, exporters and domestic firms. Journal of World Business, 42, 236-252. http://dx.doi: 10.1016/j.jwb.2007.04.012

ADB (2008). Expanding horizons: A study on the development of the Indonesia, Malaysia, Thailand Growth-Triangle Economic Connectivity Corridors Asian Development Bank.

Andreev, P., Hearty, T., Maozz, H., \& Pliskin, N. (2009). Validating formative partial least squares (PLS) models: methodological review and empirical illustration ICIS 2009 Proceedings.

Bates, J. M., Cooper, D. L., \& Wachs, P. M. (2001). Assessing wellness in college students: A validation of the salubrious lifestyle scale of the student developmental task and lifestyle assessment. Journal of College Student Development, 42, 93-203.

Becker, J. M., Klein, K., \& Wetzels, M. (2012). Hierarchical latent variable models in PLS-SEM: guidelines for using reflective-formative type models. Long Range Planning, 45(5-6), 359-394. http://dx.doi: 10.1016/j.1rp.2012.10.001

Biel, A. L. (1992). How Brand Image Drives Brand Equity. Journal of Advertising Research, 32(11), 6-12.

Blackwell, R. D., Miniard, P. W. \& Engel, J. F. (2001). Consumer behavior Orlando, FL, Harcourt.

Bollen, K. A. (1989). Structural equations with latent variables, New York, Wiley. http://dx.doi.org/10.1002/9781118619179

Chaney, D. (1996). Lifestyles, London, Routledge.

Chen, T. Y., \& He, Q. Y. (2006). Applying decision tree techniques to segmentation bases for e-marketing. Management Science Research, 3, 1-25.

Chin, W. W. (1998). The partial least squares approach to structural equation modeling. In: MARCOULIDES, G. A. (ed.) Modern Methods for Business Research. Mahwah, NJ: Lawrence Erlbaum Associates.

Demby, E. (ed.) (1974). Psychographics and from Where it Came, Chicago, IL: American Marketing Association.

Diamantopoulos, A., \& Siguaw, J. A. (2006). Formative versus reflective indicators in organizational measure development: A comparison and empirical illustration. British Journal of Management, 17(4), $263-282$. http://dx.doi: 10.1111/j.1467-8551.2006.00500.x 
Efron, B., \& Tibshirani, R. J. (1994). An introduction to the bootstrap, CRC press.

Fornell, C., \& Larcker, D. (1981). Evaluation structural equation models with unobservable variables and measurement error. Journal of marketing research, 18(1), 39-50. Retrieved from http://www.jstor.org/stable/3151312

Ghisseli, E. E., Campell, J. P., \& Zedeck, S. (1981). Measurment theory for the behavioral sciences San Francisco, CA, Freeman.

Götz, O., Liehr-Gobbers, K., \& Krafft, M. (2010). Evaluation of structural equation models using the partial least squares (PLS) approach. In Esposito-Vinzi, V., Chin, W. W., Henseler, J., \& Wang, H. (Eds.), Handbook of partial least squares: Concepts, methods, and applications. Berlin, Germany: Springer-Verlag. http://dx.doi.org/10.1007/978-3-540-32827-8_30

Gotz, O., Liehr-Gobbers, K., \& Kraft, M. (eds.) (2010). Evaluation of strucutral equation models using the partial least square (PLS) approach, Heidelberg: Springer.

Green, G. T., Cordell, H. K., Betz, C. J., \& DiStefano, C. (2006). Construction and validation of the national survey on recreation and the environment's lifestyles scale. Journal of Leisure Research, 38(4), 513-35.

Hair, J. F., Hult, G. T., Ringle, C. M., \& Sarstedt, M. (2013). A primer on Partial Least Squares Structural Equation Modelling (PLS-SEM), Thousand Oaks, California SAGE Publications, Inc.

Hair, J. F., Ringle, C. M., \& Sarstedt, M. (2011). PLS-SEM: Indeed a silver bullet, Journal of Marketing Theory and Practice, 19, 139-151. http://dx.doi:10.2753/MTP1069-6679190202

Hair, J. F., Sarstedt, M., Ringle, C. M., \& Mena, J. A. (2012). An assessment of the use of partial least squares structural equation modelling in marketing research, Journal of the Academy of Marketing Science, 40, 414-433. http://dx.doi: 10.1007/s11747-011-0261-6

Hornik, J. (1989). A Temporal and Lifestyle Typology to Model Consumers' Smoking Behavior. Advances in Consumer Research, 16(1), 44-50.

Hur, W. M., Kim, H. K., \& Park, J. (2010). Food and situation-specific lifestyle segmentation of kitchen appliance market. British Food Journal, 112(3), 294-312. http://dx.doi.org/10.1108/00070701011029165

Inkpen, A. C., \& Birkenshaw, J. (1994). International joint ventures and performance: an interorganizational perspective. International Business Review, 3(3), 201-217. http://dx.doi.org/10.1016/0969-5931(94)90002-7

Jarvis, C. B., MacKenzie, S. B., \& Podsakoff, P. M. (2003). A critical review of construct indicators and measurement model misspecification in marketing and consumer research. Journal of consumer research, 30, 199-218. http://dx.doi.org/10.1086/376806

Johnson, R. E., Rosen, C. C., Chang, C. H. D., Djurdjevic, E., \& Taing, M. U. (2012). Recommendations for improving the construct clarity of higher-order multidimensional constructs. Human Resource Management Review, 22, 62-72. http://dx.doi.org/10.1016/j.hrmr.2011.11.006

Kaynak, E., \& Kara, A. (2001). An examination of the relationship among consumer lifestyles, ethnocentrism, knowledge structures, attitudes and behavioural tendencies: A comparative study in two CIS states. International Journal of Advertising, 20, 457-82.

Kucukemiroglu, O. (1999). Market segmentation by using consumer lifestyle dimensions and ethnocentrism: An $\begin{array}{lllll}\text { empirical study. European Journal of Marketing, 33(5/6), 470-487. } & \text {. }\end{array}$ http://dx.doi.org/10.1108/03090569910262053

Lazer, W. (ed.) (1963). Lifestyle Concepts and Marketing, Chicago, IL: American Marketing Association.

Lee, H. J., Lim, H., Jolly, L. D., \& Lee, J. (2009). Consumer lifestyles and adoption of high-technology products: a case of South Korea. Journal of International Consumer Marketing, 21, 153-167. http://dx.doi.org/10.1080/08961530802153854

Lin, F. Y. (2003). An analysis of hospitality consumer lifestyles in the United States. PhD dissertation, Texas Tech University.

Mitchell, A. (1983). The Nine American Lifestyles, New York, NY, Warner.

Murry, J. P., Lastovicka, J. L., \& Austin, J. R. (Eds.) (1997). The value of understanding the influence of lifestyle trait motivations on consumption beliefs, Mahwah, NJ: Lawrence Erlbaum.

Peng, D. X., \& Lai, F. (2012). Using partial least squares in operations management research: A practical 
guidelines and summary of past research. Journal of Operations Management, 30, 467-480. http://dx.doi.org/10.1016/j.jom.2012.06.002

Penz, E. (2006). Researching the socio-cultural context: putting social representations theory into action. International Maketing Review, 23(4), 418-437. http://dx.doi:org/10.1108/02651330610678985

Petter, S., Straub, D., \& Rai, A. (2007a). Specifiying formative constructs in information system research. MIS Quarterly, 31, 623-656.

Plummer, J. T. (1977). The concept and application of life style segmentation . Journal of Marketing, 38, 33-37. http://dx.doi.org/10.2307/1250164

Podsakoff, N. P., Shen, W., \& Podsakoff, P. M. (2006). The role of formative measurement models in strategic management research: review, critique, and implications for future research. Research methodology in strategy and management, 3, 197-252. http://dx.doi.org/10.1016/S1479-8387(06)03008-6

Podsakoff, P. M., MacKenzie, S. B., Lee, J. Y., \& Podsakoff, N. P. (2003). Common method biases in behavioral research: A critical review of the literature and recommended remedies. Journal of Applied Psychology, 88, 879-903. http://dx.doi.org/10.1037/0021-9010.88.5.879

Ringle, C. M., Wende, S., \& Will, A. (2005). SmartPLS 2.0 (M3) Beta. Hamburg, Germany

Struch, N., Schwartz, S. H. \& Van Der Kloot, W. A. 2002. Meanings of basic values for women and men: A cross-cultural analysis. Personality and Social Psychology Bulletin, 28, 16-28. http://dx.doi.org/10.1177/0146167202281002

Tsang, E. W. K. (2002). Acquiring knowledge by foreign partners from international joint ventures in a transition economy: learning-by-doing and learning myopia. Strategic Management Journal, 23(9), 835-854. $\mathrm{http}: / / \mathrm{dx}$.doi.org/10.1002/smj.251

Vyncke, P. (2002). Lifestye segmentation: From attitudes, interests and opinoins, to values, aesthetics styles, life visions and media preferences. European Journal of Communication, 17(4), 445-463. http://dx.doi.org/10.1177/02673231020170040301

Wells, W., \& Tigert, D. (1971). Activities, interests, and opinions. Journal of Advertising Research, 11(4), 27-35.

Yu, C. S. (2011). Construction and validation of an e-lifestyle instrument. Internet Research, 21, 214-235. http://dx.doi.org/10.1108/10662241111139282

\section{Copyrights}

Copyright for this article is retained by the author(s), with first publication rights granted to the journal.

This is an open-access article distributed under the terms and conditions of the Creative Commons Attribution license (http://creativecommons.org/licenses/by/3.0/). 